Revista de Filología Románica

ISSN: 0212-999X

http://dx.doi.org/10.5209/RFRM.63505

\title{
La formación histórica de gentilicios hispánicos en la Romania
}

\author{
Juan O. Hernández ${ }^{1}$
}

Recibido: 18 de febrero 2018 / Aceptado: 4 de septiembre de 2018

Resumen. La bibliografía académica y los proyectos de investigación más recientes sobre la "relación gentilicia" apenas se ocupan de la historia de la formación de gentilicios en las lenguas romances. La literatura sobre teorización de los gentilicios no esclarece la razón de la extraordinaria productividad gentilicia que presenta la Romania, ni aborda los antecedentes históricos de esta riqueza. Con el fin de contribuir a llenar este vacío, el presente artículo ensaya una introducción sucinta a la lexicogénesis gentilicia.

Palabras clave: gentilicios; Romania; lenguas romances; lexicogénesis

\section{[en] The historical formation of hispanic demonyms in the Romania}

\begin{abstract}
The academic literature and the most recent research projects on the "gentilic relation" hardly deal with the history of demonym formation in Romance languages. Literature on theorizing about demonyms not clarifies the reason for the extraordinary gentilic productivity that the Romance-speaking world present, nor addresses the historical background of this richness. In order to contribute to fill this gap, this article rehearses a succinct introduction to demonymic lexicogenesis.
\end{abstract}

Keywords: demonyms; Romania; Romance languages; lexicogenesis

Sumario: Introducción. 1. Lexicogénesis del gentilicio romano. 2. Latín de los cristianos y ruina casual. 3. La apertura de la marcación topo/demonomástica. Conclusión. Post scriptum.

Cómo citar: Hernández, J.O. (2019). La formación histórica de gentilicios hispánicos en la Romania, en Revista de Filología Románica 36, 45-61.

\section{Introducción}

La formación de palabras gentilicias en las lenguas romances ha concitado un creciente interés filológico en los últimos treinta años ${ }^{2}$. Dentro de este esfuerzo académico cabe destacar sendos proyectos trianuales sucesivos de investigación en 2008 y

$1 \quad$ Facultad de Ciencias Sociales y de la Comunicación - Universidad de La Laguna jhernanc@ull.edu.es

2 Ferreccio Podestá y Jocelin Hernández 1992; Schweickard 1992, 2002-2013; Herrera 1997; Monjour 2002; Reinhardt 2010; García Gallarín 1997; Muñoz Cordero y Ordóñez Arbizu 2009; Navas Sánchez-Élez 2012; Kordić Riquelme y Ferreccio Podestá 2014; Morera 2015; Chávez Fajardo y Kordić Riquelme, en prensa. 
2011, adscritos al Instituto Universitario de Lingüística Andrés Bello y dirigidos por Marcial Morera, catedrático de Filología Española de la Universidad de La Laguna, que han contribuido con una variada producción teórica al conocimiento de este material idiomático. ${ }^{3}$

El esquema básico empleado por este equipo de investigadores para discriminar las formas de la "relación gentilicia" fue dividido en tres modalidades tipológicas por el también catedrático de la misma Facultad Gonzalo Ortega Ojeda, en su catalogación de apodos y gentilicios de Canarias (2007:497 y 2008:18):

a) Variante sintáctica preposicional, mediante preposición $d e+$ topónimo (de Tenerife).

b) Variante morfológica derivacional, mediante sufijación del topónimo formando un adjetivo relativo (top. tinerf + suf. - eño $=$ tinerf-eño).

c) Variante lexical de supleción por un sobrenombre, apodo o mote a partir de calificativos $($ tinerfeño $=$ chicharrero $>$ chicha $)$.

Una cuestión que ha quedado sin respuesta es cómo han llegado estas tres fórmulas típicas, o alternativamente las propuestas por Mario Ferreccio, ${ }^{4}$ a vincularse para satisfacer la función gentilicia, qué circunstancias históricas hicieron posible que palabras muy diferentes, a menudo ajenas al latín, se normalizaran con naturalidad para designar una gens.

\section{Lexicogénesis del gentilicio romano}

La formación de gentilicios es tan rica y múltiple en las lenguas romances por herencia de la latinidad. La onomástica romana constituye "un sistema de nomenclatura único entre los pueblos indoeuropeos" (Dinarés Cabrerizo 2014:53), que incorporó demónimos con cierta frecuencia como fórmula de indicación de ciudadanía de origen o procedencia en estructuras patronímicas complejas (Salway 1994), sobre todo a través del cognomen, que ha sido profusamente estudiado a partir de la epigrafía y del derecho romano (González Fernández y Molina Gómez 2011). Cabe mencionar tres notas características en relación con esta etnonimia:

a) Utilización por "originalidad": como en la sociedad romana se daba prioridad a determinar el grupo cívico familiar en la composición nominal, así como el vínculo honorífico o dinástico del portador, la escasa productividad onomástica dificultaba la identificación individual de cada persona, dada la multiplicación de nombres repetidos que reproducían, por ejemplo, las extensas relaciones clientelares. Esta situación se resolvió añadiendo cognomina y agnomina como apodos o sobrenom-

Llevaron por título Estudio global de los gentilicios de la lengua española y Estudio global de los gentilicios de la lengua española: materiales americanos, nuevas consideraciones teóricas y gestión informática de los datos. Una presentación sucinta de cada proyecto puede leerse en Morera 2012:69 y 2013 [en prensa]. La lista de miembros de este grupo de investigación, así como una relación de sus publicaciones y actividades puede consultarse en: http:/gentidb.saii.ull.es/actividades/. Para una síntesis teórica de estos trabajos, Martín Padilla 2015.

4 Onomasiológica, funcional y morfológica Ferreccio Podestá y Jocelin Hernández 1992:10-11). 
bres discriminantes, que pasaban a las ramas familiares perdiendo la connotación geográfica. Como la unidad territorial esencial a efectos fiscales era el municipio, la consignación escrita del origen local distinguía también el domicilio fiscal, la obligación legal de contribuir a las cargas derivadas de la residencia en una ciudad. Pero como la función principal de estos etnónimos era distinguir al ciudadano, su tratamiento morfo-sintáctico y casuístico no desarrolló notas específicas destacables y fue el común a la generalidad del adjetivo o nombre calificativo.

b) Inscripción por "alienabilidad": en el tratamiento epigráfico era común que se empleara el etnónimo de domus, origo o natio como complemento para identificar la procedencia de personas (epitafios funerarios) o grupos (exvotos tribales) que no pertenecían al lugar de la inscripción o tenían distinto origen provincial o étnico. Aunque había excepciones a esta práctica, normalmente estos epígrafes indican desplazamiento. En especial, debido a la movilización entre provincias de soldados reclutados en grupos "tribales" determinados, que conformaban unidades auxiliares marcadas étnicamente, el señalamiento de la patria de origen fue muy frecuente como expresión de "alienabilidad", al darles sepultura lejos de su tierra natal con ocasión de operaciones bélicas o defensivas de larga distancia (Perea Yébenes 2005).

c) Expresión de "territorialidad" en la ciudadanía ecuménica: el Edicto de Caracala de 212 universalizando la ciudadanía romana vació de contenido distintivo las denominaciones familiares discriminantes, motivando el recurso a la agrupación nominal por domicilio y territorio como nuevo criterio diferenciador (D'Ors Pérez-Peix 1946:603-604). Por esa razón, el propio término gentilicio dejó de connotar la pertenencia a una familia para referirse específicamente a la localización en un lugar, como lo entendemos hoy.

Otro ámbito de creación del léxico gentilicio romano fue la literatura analítica, donde la sobreabundancia de etnónimos era una marca de estilo que se debió, tanto a la influencia determinante de fuentes helenísticas, como al interés por poblaciones que éstas no habían descrito, que excitaron las "preocupaciones etnogeográficas de los historiadores latinos" durante la expansión imperial (García Moreno 1994:7677). Esta los convirtió en "enthusiastic ethno-hunters" (Whittaker 2009:189-90), con tres sentidos principales: categorías generalizadas, como germanos o escitas, connotativas de origen pero sin referentes de autoidentificación entre los así llamados (Solodow 2010:49-50); gentilicios de la interfaz periférica romana, correspondientes a grupos integrables en determinadas condiciones y con cierto grado de autonomía; y vecinos bárbaros, tanto aliados temporales, como irreconciliables o enemigos de la romanización (Pohl 2015a:202-203). Para evitar el desagrado de sus lectores, los escritores adaptaron con fines eufónicos la extraña sonoridad de los gentilicios indígenas al oído de sus destinatarios, latinizándolos (Brodersen 1995:117), anticipando la práctica habitual en las lenguas románicas. Pero cabe distinguir, en relación con la etnicidad de estos grupos humanos exóticos a ojos romanos, la coexistencia de un lenguaje literario y de ficción con otro funcional y de inteligencia estatal o militar, necesariamente realista:

Roman propaganda could certainly fantasize about 'barbarians' in triumphal inscriptions and panegyric poems, and give them antiquated or imaginary names; some of which might also appear in works of ethnography or historiography. But we have enough evidence to see that in their diplomatic and military contacts with 
foreign gentes, the Romans relied on excellent intelligence. On the whole, their perception of ethnic groups around them was adequate and allowed them some form of control over their 'barbarian' periphery for many centuries (Pohl ibid.).

Esta doble capa de la tipología gentilicia, triple si incluimos la genuinamente indígena, parece ser una conducta lingüística intemporal, repetida a lo largo de siglos en todos los territorios sujetos a colonización y/o descolonización hasta hoy, que actúa como factor multiplicador de la nómina gentilicia. ${ }^{5}$

La construcción del Imperio romano con otros pueblos fue una intensa e inmensa obra de catalogación o logos apofántico de inspiración helenística. ${ }^{6}$ En época homérica se conservaba una tradición catalográfica preliteraria que refleja una devoción muy temprana por las listas antroponómicas, toponomásticas y demonómicas en el Levante mediterráneo antes del primer milenio a. C., debido a influencias orales asirias, anatolias y micénicas que alcanzaron a Homero en el siglo VIII y tienen su expresión más conocida en el Catálogo de las Naves del Canto II de la Ilíada (González García 1997) y el género periplográfico que describe los pueblos costeros contactados en viajes de larga distancia e itinerarios sagrados (Bocchetti 2006).

El modelo de la geografía y etnografía romanas fue esencialmente helenocéntrico. ${ }^{7}$ Imitaba la pasión descriptiva griega que va de Heródoto a Estrabón y condujo a esa suerte de fruición onomástica y paradoxográfica de enciclopedistas como Pomponio Mela y Plinio por los pueblos periféricos y exóticos, que alcanza su madurez con las campañas de César y la obra de Tácito (Molina Marín 2011:257-309). Estrabón consideraba un motivo para escribir su Geografía la manera en que Roma estaba transformando a las gentes que absorbía, "bajo cuyo dominio, la mayoría de los pueblos han perdido ya tanto sus dialectos como sus nombres, al haber sido dividido el territorio de forma distinta" (Geografia 12.4.6; Dandrow 2017:122).

\begin{tabular}{|lccr|}
\hline Colectivo & & & Comunal \\
Parentesco & Historia & Territorio & Comunidad \\
Trans-regional & Helenidad & Regional (ethnē) & Poleis \\
Eolios & Helenos & Foceos & Samios \\
& & & \\
\hline
\end{tabular}

Fig. 1: Esquema de los niveles de la etnicidad griega en la Antigüedad, según Vlassopou$\operatorname{los}(2015: 12)$.

La multiplicidad de formas que presentan los demónimos en las lenguas romances puede explicarse como un efecto del estrés lingüistico que supuso para el latín tener que improvisar nombres y adjetivos a uña de caballo para registrar el conocimiento, el contacto y la incorporación de nuevos territorios y poblaciones a una

\footnotetext{
5 Se trata de una realidad común en toda Hispanoamérica, demostrada empíricamente durante el trabajo de campo de rescate y registro de gentilicios dirigido por Mario Ferreccio en Chile (Kordić Riquelme y Ferreccio Podestá 2014:10).

6 Sobre el concepto de logos apofántico en relación con los gentilicios (Almela Pérez 2013:14).

7 Para la cuestión de la etnicidad en la historiografía clásica griega el texto fundamental sigue siendo Hall (1997) v. tb. (et al. 1998 y 2002); discusión con Vlassopoulos (2015:1-13 y 15-29).
} 
escala masiva de préstamos léxicos no prevista en su sistema nativo de flexión nominal. El proceso dejó un rastro de formas heteróclitas en la toponimia para normalizar en latín nombres griegos, prehelénicos o helenizados, o de muy diverso origen, que determinaron la morfología del gentilicio correspondiente, a menudo dual u oscilante en cuanto al género gramatical y la flexión (González Luis, 2003:139). Esta peculiar fenomenología podría explicar la complejidad, variabilidad y diversidad morfo-sintáctica, gramatical y semántica que presentan los gentilicios en las lenguas romances, donde en italiano hay unos 50 sufijos demonímicos diferentes, además del sufijo cero y las formas perifrásticas (Marcato 2009:199) mientras la formación de gentilicios en las lenguas eslavas, por ejemplo, sólo desarrolló uno (Lisyovà 2005:258). En cuanto adjetivos de relación, los gentilicios derivativos de nombres de lugar "forman parte de la categoría derivacional más importante numéricamente hablando de la lengua española, con más de 70 sufijos" (Kordić Riquelme y Chávez Fajardo 2017:222).

Sospechamos que la normalización de esta permeabilidad y flexibilidad, que prescindió de una marcación específica en latín y aplicó con carácter general preposiciones, conjunciones subordinantes y desinencias casuales a extraños nombres colectivos sobrevenidos, es en última instancia la razón que favoreció la normalización del recurso a gentilicios raros en época medieval para denominar pueblos en las sucesivas etapas expansivas de Cruzada hacia el Levante y el Atlántico, que simbolizan en cartas portolanas sendas cruces de gules sobre Rodas y Lanzarote, los dos extremos de la ecúmene papal en la Europa trecentista. La materia de Bretaña emuló la literatura geográfica latina introduciendo el gusto por lo exótico y las islas lejanas en las lenguas vernáculas antes de la amplia difusión de los grandes clásicos. ${ }^{8}$ Cuando a partir de 1330 los cartógrafos comienzan a representar las insulas noviter repertas del Atlántico, envueltas aún en un halo de misterio náutico, las bautizan alegremente con denominaciones extraídas de la literatura de ficción, tales como Lanzarote, Alegranza/Graciosa, Infierno, Gomera, Senza Ventura, Forte Ventura, ${ }^{9}$ que prefiguran algunos de los futuros gentilicios por derivación (gomero, lanzaroteño, graciosero).

Las lenguas románicas ya estaban preparadas para que palabras como guanche (natural de Tenerife) pudieran funcionar plenamente como gentilicios en español en el siglo XV, a pesar de su opacidad idiomática y semántica, con ocasión de la expansión atlántica. En este sentido, apenas se diferencia de las denominaciones étnicas subgrupales adaptadas externamente por los etnógrafos romanos, que no contaban necesariamente con afinidad auto-referencial entre las gentes que identificaban, pues habían dejado de ser lexías funcionales en cualesquiera que fueran las lenguas originales, para convertirse en un distintivo o etiqueta de pertenencia cuyo sema quedaba instantáneamente obliterado en latín, si no es que era directamente sustituido en segunda generación por uno latino, cuando el cognomen bárbaro denotaba información depreciativa, como el origen esclavo (Kajanto 1968:521).

8 Las fuentes medievales principales para el estudio de las islas hasta el siglo XIV son Orosio, Isidoro y Hugo de San Víctor. Fuera de los recentiores, un conocimiento geográfico directo a través de otros autores clásicos es inhabitual antes del Renacimiento. La Geografia de Ptolomeo de Planudes (c. 1300) no alcanza Europa hasta principios del siglo XV con la reintroducción del griego por los exiliados bizantinos. Son tardías las impresiones príncipes de Plinio (Spira 1469) y Tucídides (Partenio 1483).

9 Las denominaciones de las Islas Canarias en las cartas portolanas de 1330 a 1375 probablemente coinciden con las de obras hoy perdidas como la Inventio Fortunatae y el Itinerario de toda Asia, Africa y el Norte (c. 1363), que significativamente remiten a la Gestae Arthuri (Enterline 2002). 


\section{Latín de los cristianos y ruina casual}

Este proceso lexicogenético derivado de la expansión imperial expuso inevitablemente al latín a inesperadas influencias culturales exógenas y exóticas en materia demonomástica, siendo la adopción del cristianismo la más importante por su naturaleza escrita (la Biblia $=$ el Libro), su ascendencia griega (la Septuaginta) y su transversalidad homogeneizadora en toda la población romana; una religión que, aunque inicialmente dividida en distintas y antagónicas confesiones (donatistas, arrianos, católicos, etc.), se sobrepuso a la división en los reinos germánicos, dando lugar a la familia romance. ${ }^{10}$ Entre los siglos II y IV d. C. el latín bíblico de la Vetus Latina y la Vulgata (García de la Fuente 1990:50) o "latín de los cristianos dentro del latín tardío" (Ortuño Arregui 2016:60; Bastardas 1973; Lorenzo 1976; García de la Fuente, 1987), "resultante final de un sistema de convergencias lingüísticas constituido por el hebreo-arameo, el griego y el latín vulgar de la época en que se tradujo la Biblia al latín" (Ramírez Olid 1988:401), introdujo múltiples hebraísmos étnicos a través del griego, como cananeos, hebreos, fariseos, filisteos [sufijo-aeus], israelita, ismaelita, carmelita, moabita [sufijo -ites, -itis, -itidis], etc. (García de la Fuente 1981:319-320; 1994:245). Ocasionalmente, la doble latinización, temática y atemática (arabs/arabes, aethiops/aethiopis) a partir del genitivo singular griego, contribuyó a la marcación preferente de los gentilicios en masculino asimilado al neutro latino, característico de las lenguas romances (González Luis, 1995: III,1179). También entraron en el vocabulario arameísmos como sarraceno o samaritano (Sadak 2000:213; Ortuño Arregui 2008:260). Esta efusión gentilicia se debió a una marcada característica del cristianismo, su continuo recurso a la clasificación étnica dentro de un esquema de universalidad formal:

[...] perhaps surprisingly, the ethnic framing for the new kingdoms was supported by Christianity. The Old Testament offered a rich repertoire of ideas to support an ethnic view of the political world [...] However universal a doctrine Christianity presented itself as, its holy books reserved an important role for ethnicity (Pohl 2015a:205).

La sintaxis de los textos cristianos originales en hebreo se trasladó directamente a las traducciones bíblicas griegas y latinas, alterando el orden de las palabras en las frases, preludio de la sintaxis romanceada (García de la Fuente 1994:240-241). La documentación eclesiástica introdujo nuevas fórmulas de apariencia cognominal (García Gallarín 2003:585-586), tipo nombre propio + cargo + gentilicio como Marinus burgensis Ecclesiae Episcopus (1234) o Melchioris Cani Episcopi Canariensis ex Ordine Praedicatorum (1734).

Además de estos rasgos evolutivos, la idea de un paso del latín al romance suele omitir el hecho notorio de que en la bastedad geográfica del aire romano el latín cotidiano era hablado por el vulgo tirando a las lenguas nativas de cada cual. Desde

10 Hacia el siglo VI un reino ostrogodo regía Italia, otro vándalo se había enseñoreado del Norte de África, los visigodos gobernaban la península ibérica y en la Galia se había instaurado un reino franco (Pohl 2015b:28). Para la problemática de la gens en la sustitución del imperium por los regna, Goetz (2003b) y Pohl (2014). Un análisis léxico sobre el uso de términos etnoterritoriales por algunos historiadores del período (Orosio, Gregorio de Tours, Fredegario) y en tres anales/crónicas Carolingias, en Goetz (2003a:52-61). 
el principio de la romanización, el latín fue para estos pueblos la lengua común o lingua franca que no dejaba de entenderse aunque se hablara mal, hábito que explica por qué siempre es discutible fijar rígidamente una cronología post quem para algunos fenómenos asociados al latín de los cristianos y la transición romance. Los problemas de calibración que la separación de las lenguas románicas plantea continúan muy vivos en la dialectología (Pereltsvaig y Lewis 2015:106-113). El fenómeno lingüístico más determinante para la variación gentilicia en castellano fue la generalización del sintagma preposicional con de frente al sistema de casos latino, generando desde época clásica una creciente preferencia por la matización sintáctica en lugar de la marcación morfológica.

El examen de la preposición de con sentido de origen, separación o procedencia en la obra monumental de Baños (2009) sobre la sintaxis latina, así como otras tres contribuciones significativas de Hernández Cabrera (1998), Company (2014) y González Saavedra (2015), apunta a una ventaja de $d e+$ abl. por su carácter neutro, unido a la puntualización o concreción expresiva, factores que motivan su uso extensivo, simultáneo al alejamiento progresivo de la norma casual. Así mismo, la preposición de se extiende a la marcación de complementos adnominales para codificar funciones de cualidad propias del genitivo próximas al ablativo, expresando que " $a$ está subordinada a $b$ ", asimilable a procedencia. Esta genitivización gradual, que transforma nombres en adjetivos como en el indoeuropeo, es "una de las innovaciones más llamativas de esta preposición en su evolución del latín al romance", mediante un proceso sustitutivo: genitivo $>d e+$ ablativo $>d e+$ sustantivo sin caso, para expresar la adnominalidad del genitivo.

El cambio consistió en dos hechos concomitantes: la sustitución del genitivo a favor de de + ablativo y la gran extensión de la preposición de en las lenguas romances para codificar relaciones de adnominalidad. La innovación debió producirse, posiblemente, ya en época clásica [y] debió generalizarse al erosionarse el sistema casual latino por completo (Company 2014:1379).

Entre los siglos VI y IX, la ruina de la declinación, el confusionismo o sincretismo casual, habría conducido a una variación arbitraria, desviante o aberrante de las terminaciones caso + sintaxis exigidas por las reglas del latín clásico (Cardoso 2002:45). La preservación de manuales de corrección del latín vulgar como el Appendix Probi así lo demuestra (Solodow 2010:114-120). Los escribas prescinden de la coherencia sintáctica en la marcación, bien por vulgarización, o bien por hipercorrección con pretensiones eruditas, a menudo fallidas por la selección aleatoria de la terminación casual, como se lee en la documentación notarial. A partir del momento en que la función sintáctica se expresa mediante un sintagma preposicional con de + sustantivo, los morfemas flexionales del caso (genitivo o ablativo) dejan de ser interpretados como marcadores de la misma, tendiendo a ser inaprensibles para el locutor (Cardoso 2002:80). Esto produce la acentuada generalización de un caso oblicuo o caso Ø que supondrá, con la caída de los sonidos finales, la liberación definitiva de las bases del sustantivo y el adjetivo del sistema casual latino. ${ }^{11}$ Alternativamente, este cambio condujo de manera simultánea al

11 Galo-Romance, Ræto-Romance y Daco-Romance mantuvieron residualmente el sistema de casos, que se conservó específicamente en rumano (Ledgeway 2012:333; Stan 2014:56:56). 
realce de la sufijación morfológica de connotación conservada en el latín vulgar y ampliada por el latín de los cristianos, que es fundamental para entender la construcción de la función gentilicia en las lenguas romances (canarii/canariorum $>$ de Canaria $>$ canario $>$ canariensis $>$ canariense).

En conclusión, al final del proceso formativo de las lenguas romances nos encontramos con la generalización de los sintagmas preposicionales con de + sustantivo indeclinado, donde se acopla el gentilicio sintáctico formado sobre topónimos o demónimos con referencia específica a gentes, a la vez que se han conservado formas sufijales de las lenguas que habían precedido y entrado en contacto con el latín durante la expansión romana, la cristianización y la subsiguiente disgregación germánica de la latinidad. Así, cada lengua romance reabsorbió una multiplicidad antieconómica de sufijos que no correspondían a su propia evolución natural, sino eran relictos funcionales heredados de la lengua común del Imperio, produciendo el cuadro enciclopédico que actualmente presenta la función gentilicia, considerado problemático, inclasificable, poco regular o caótico (Almela Pérez 2013:15; Pérez Vigaray 2015:252). Al mismo tiempo, los nuevos gentilicios retuvieron residuos desinenciales, no funcionales propiamente como las antiguas desinencias categoriales, que se ha dado en denominar semidesinencias o seudodesinencias.

En la península ibérica la situación para el español y el portugués fue todavía más compleja, debido a la influencia de la lengua árabe ${ }^{12} \mathrm{y}$, finalmente, los pueblos indígenas de América también introdujeron algunos sufijos en la formación de gentilicios. ${ }^{13}$ En Canarias son cultismos del español los supuestos gentilicios indígenas, transmitidos por transcripciones realizadas al oído por no hablantes, lexemas romanceados de autoctonía poco fiable debido a la fuerte carga mitológica y legendaria asociada al descubrimiento y colonización, combinada con una rápida marginación, desuso y extinción de las antiguas hablas isleñas durante los siglos XV y XVI.

\section{La apertura de la marcación topo/demonomástica}

Los sufijos no arbitran la designación gentilicia. Puede hablarse con propiedad de sufijos con función toponomástica o demonomástica, ${ }^{14}$ en lugar de sufijos gentilicios, pues la exclusividad de la función gentilicia no reside en el sufijo (ninguno de los sufijos presentes en los gentilicios es de uso exclusivamente gentilicio), sino en la base léxica, es decir, en el topónimo o demónimo que rige la idea de origen, pro-

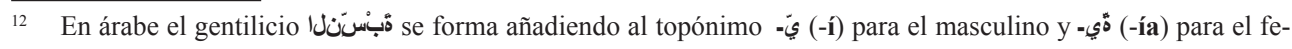
menino, terminaciones presentes en ceutí, marroquí, yemeni, etc.

13 De atribución náhuatl en el español de México es el sufijo -eco, presente en guatemalteco, yucateco, tlaxcalte$c a$, etc. A los que hay que añadir los denominados sufijos gentilicios hápax, detectados en Chile por Kordić y Chávez (2017:229).

14 Con otra terminología onomasiológica: función postoponímica, entendida de aquellos gentilicios derivativos, articulados por derivación adjetival a partir de un topónimo o nombre demográfico, "en su estructura semántica el nombre de lugar actúa como núcleo o materia básica de la combinación con un sufijo" (Kordić Riquelme y Chávez Fajardo 2017:218); o bien, función étnica "nombres que designan razas, etnias, los cuales no son morfológicamente (al menos en principio y haciendo abstracción de lo que pudiera descubrir en ellos una penetración etimológica) derivados, sino primitivos, que pueden gestar, al revés, un topónimo, el cual pasa a denominar los parajes adonde llegaron a instalarse aquellos pueblos: ruso, turco, alemán generan respectivamente Rusia, Turquía, Alemania, topónimos que son, ellos sí, derivados" (Ferreccio Podestá 2006:179). Si bien, estos autores no dejan de señalar que sustantivos étnicos y derivados adjetivales postoponímicos se mezclan con frecuencia. 
cedencia, localización, separación o pertenencia mediante el sufijo. Esto explica por qué la dación de unos sufijos u otros es tan arbitraria en el habla, no está prefijada por la norma semántica ni gramatical que los ha creado. Lo mismo puede decirse de las desinencias de género o número, llegan a perder toda eficacia significativa en la función gentilicia.

El sema de un gentilicio está concentrado en la raíz toponímica o étnica del sustantivo o adjetivo, es decir, si el sufijo acompaña a un lexema que es un topónimo o demónimo, automáticamente significa una función gentilicia frente a otras posibles, excepto cuando el contexto pueda establecer sentidos calificativos o connotativos distintos al de procedencia (gitano en "¡Vaya un gitano!”, fenicio en "¡Menudo fenicio estás hecho!", chino en "Esto no lo resuelve ni el médico chino" o guanche en "Alto como un guanche").

Los sufijos de los gentilicios no son atributos, sino marcaciones del topónimo o demónimo al que se unen. Hay, en efecto, reglas generales de afijación, pero estas nunca determinan la elección de uno u otro afijo. La sufijación gentilicia no es normativa, sino histórica, no añade una regla, sino un color, un aire lingüístico o idiomático de evocación; si cada sufijo tiene una historia, el resultado de su conservación e imposición es contingente, no determinado por normas inflexibles. ${ }^{15}$ Dependiendo históricamente de cada habla particular que ha contribuido, a lo largo del tiempo, prestando morfemas o alomorfos de sufijación propios al corpus léxico de una lengua común (como el latín), los sufijos de los gentilicios romances no pueden ponerse en un plano sincrónico a efectos de clasificación. La comparación de un sufijo con otro remite inevitablemente al relato de cómo y cuándo entró en la lengua, antes que a su funcionalidad (por ejemplo, en donostiarra el sufijo -arra tiene origen mediterráneo preindoeuropeo, anterior a la presencia del latín en la península ibérica).

Pero el final del sistema casuístico del latín y el recurso al sintagma preposicional $d e+$ sustantivo indeclinado generaron otro fenómeno de apertura en la designación gentilicia: la posibilidad del sobrenombre o apodo, técnicamente denominados alogentilicios léxicos, paragentilicios o pseudogentilicios (García Padrón 2012:152; Tabares Plasencia 2015:170,172), con plena libertad para usar cualquier palabra que coloree al regente incluso sin sufijo, sin perder el carácter de identificador colectivo, dependiendo solamente del consenso interpretativo entre los hablantes, es decir, de una contextualización aprendida de esa expresión para entenderla como gentilicio en lugar de las fórmulas habituales preposicionales o sufijadas. La posibilidad de suplir la forma regente + terminación por un nombrete o remoquete que absorba toda la significación del constructo gentilicio abre la lengua todavía más a la normalización, naturalidad y funcionalidad de exotismos (exónimos), pues permite crear cápsulas en el idioma, que el hablante utiliza como un comodín lingüístico, es decir, como una estructura comprensible dentro de la función designativa, que permite la inteligibilidad de casi cualquier lexema que ponga dentro de ella, que Ferreccio Podestá denomina designativos enterizos, tratados sin marcación en el plano onomasiológico (2006:181).

La alienación de un pseudónimo puede llevarse al extremo de emplear voces completamente ciegas a su propia naturaleza, incapaces de proyectar una imagen

15 En este punto diferimos de Morera y coincidimos con García Sánchez en que "cuesta admitir [...] que cada sufijo de los aplicados a los gentilicios tenga una significación particular en ellos" (2017:540), y con Ferreccio Podestá: “[...] las desinencias y afijos tienen, a lo más, 'valor de lengua' conocido por el usuario, pero no un significado denotativo eficiente" (2006:180). 
determinada que los hablantes puedan compartir. Esta es la última fase de la integración de palabras exóticas como guanche. Se puede decir y comprender funcionalmente porque ocupa el lugar de un gentilicio, aunque se discuta su origen y etimología. Pudo funcionar sin estridencia dentro de las lenguas románicas como un apodo gentilicio, compartiéndose entre ellas sin apenas modificaciones formales o fonéticas para designar a los antiguos habitantes de Tenerife o de Canarias. Pero, aunque el hábito en el habla pueda presentárnosla como una palabra común, lo cierto es que cinco siglos después de que entrara en el español o el portugués sigue siendo rarísima, casi completamente opaca.

En este sentido, los exotismos designativos caminan junto a los apodos o los neologismos: aunque hubieran sido nombres o adjetivos normales en una lengua matriz anterior, sujetos a sus reglas morfo-sintácticas y gramaticales, ahora su empleo como pseudónimos formatea o prescinde de todas esas notas o marcaciones, pues su utilización está presidida por el ánimo de jugar con la forma externa de la palabra, no con su contenido original. Esta naturaleza a la vez usual e impenetrable de un vocablo común es un legado precioso de la Romania, precisamente, el tipo de característica que atrae la atención del lexicógrafo.

\section{Conclusión}

En la brevedad de estas páginas apenas hemos apuntado unas coordenadas o pinceladas de estudio acerca de la formación histórica de la "relación gentilicia" en la Romania. El tema conduce inevitablemente al relato étnico, territorial o demográfico y al trasunto de las circunstancias modificantes que sufrió el latín, un problema dialectológico que está lejos aún de ser resuelto. La atracción mutua con las lenguas indígenas que contactó la expansión romana y la cristianización hasta la conformación romance aún continuó extendiéndose por el Levante y el Atlántico durante la Edad Media y el Renacimiento. La subsunción casuística en formas preposicionales, sufijadas y calificativas completa el cuadro descriptivo de la variabilidad morfológica que se fue consolidando en las lenguas romances a lo largo del tiempo, hasta configurar esa productividad léxica que hoy sigue asombrándonos.

\section{Post scriptum}

La hipótesis Trapero/Llamas (Llamas Pombo, 2004; Trapero, 2007) propone que guanche es cognomento galorrománico atribuido a la población nativa de las Islas Canarias durante la ocupación normano-gascona del primer cuarto del siglo XV, a partir del deverbal homónimo del francés medio ganchir "esquivar, evitar". Desde el punto de vista de la lexicografía histórica, la hipótesis es poco cuidadosa con la localización y cronología de las variantes que maneja, constituyendo una objeción la forzada desubicación espacio-temporal de la palabra en la reconstrucción que se propone: ni está adecuadamente justificada la clasificación de guanche como gasconismo, pues la voz se presenta igualmente en Normandía, ni "se hallaba en pleno uso a principios del siglo XV" (ibid. p. 786; ibid. p. 191), pues fue progresivamente sustituida por gauchir a lo largo del siglo XIV y así la trae, por ejemplo, el Livre des 
faits de Jean le Meingre, dit Boucicaut, escrito entre 1406 y 1409, contemporáneo de la expedición a las Islas Canarias y de la primera redacción de Le Canarien. ${ }^{16}$ Emplear acrónica y atópicamente solo la variante francesa que por homofonía coincide con el etnónimo guanche es razón de falsabilidad, pues no se explica por qué se privilegia entre distintas opciones disponibles precisamente aquella que más conviene a la hipótesis planteada, atribuyendo a posteriori una cronología y localización imprecisas, obviando que la adopción de gauchir en lugar de ganchir en el siglo XV es hecho indubitado y que guanche se halla en desuso en francés cuando se supone que fue otorgado como gentilicio a los isleños. ${ }^{17}$

La variabilidad de las voces derivadas del germánico *wenkjan es extremadamente compleja: en primer lugar, guenchir "vacilar" se cruzó por homofonía con gauch(i)er, del germánico *walkan "pisar", hasta confluir en gauchir; en segundo lugar, se ha admitido que *wenkjan fue introducida en dos momentos diferentes, a mediados del siglo III desde Rhenania y hasta mitad del siglo V por los letos y colonos germanos desplazados por la romanización, generando dos corrientes paralelas de variación, en $/ \delta /$ y en $/ k /$ (Moroldo, 2015), que explica que junto a variantes como guanche homófonas de nuestro etnónimo, aparezcan otras a partir de wainkir (cf. guenchir) en el área septentrional (normano-picardo, cauchois), ${ }^{18} \mathrm{o}$ bien, gingar (cf. guincher) o guigner/guinhar (cf. guincha) en el área meridional (gascón, languedociano). En tales circunstancias, la supuesta homofonía del francés medio guanche con el gentilicio español guanche no es razón válida ni suficiente para trazar directamente la identidad etimológica, frente a otras posibilidades del habla de los expedicionarios, que no puede prejuzgarse.

Pero, incluso pasando por alto estos indicios, en el plano morfológico emergen también discrepancias que comprometen la viabilidad de la hipótesis. Aunque un recurso lúdico-hipocorístico como seudogentilicio al deverbal medieval guanche, desde ganchir, pudiera haber sido conjeturable omitiendo las objeciones lexicográficas ya señaladas, el género femenino que presenta la lexía francesa propuesta (la guanche, les guanches), no concuerda con la marcación gentilicia prototípica en masculino (plural) de indiferenciación asimilada al neutro latino, que sería esperable por neutralización de la oposición privativa mediante el elemento genérico no marcado, negativo, extenso, débil o inclusivo. En otras palabras, la designación monosémica escogida no comprende la ambivalencia de género, es decir, no permite la indistinción de sexo en el plano léxico y, por eso, resulta normativamente improbable que originara la designación polisémica ambigenérica (los guanches) que la lexía presenta en las fuentes primarias castellanas de la última década del siglo XV.

16 Uno de los dos comandantes de la expedición, Gadifer de La Salle, fue de hecho compañero de Boucicaut en algunos lances.

17 Llamas Pombo (2004:791) obtiene dos ejemplos tardíos de guenchir en Le Chevalier du Papegau y la Histoire des seigneurs de Gavre, pero debe puntualizarse que no son manuscritos de datación segura por tratarse de copias que conservaron textos o pasajes de originales precedentes, y no está demostrado que reflejaran formas de hablar contemporáneas del siglo XV, pues el estilo cortesano, artúrico y caballeresco de esta clase de obras parodia a menudo por translatio los cánones referenciales de la chanson de geste, incluido el recurso lírico a los provenzalismos, como en el Papegau, o a secuencias textuales trasladadas en su literalidad de otros relatos que pueden ser muy anteriores, como en el Gavre (que plagia material lexical del Florimont, del Blancandin, etc.). No se puede deducir de estas ocurrencias de guenchir la vigencia de guanche en el francés o el gascón cuatrocentista fuera de la literatura culta.

18 Dialecto de Caux, patois hablado por Jean de Béthencourt y su hueste normanda. 
Ya que guanche debía ser un significante que designara tanto la noción "varón indígena" como la categoría "persona indígena", no se explica cómo en francés medio o gascón pudo escogerse un sustantivo desprovisto de función categorizadora por flexionarse en femenino inherente de una sola terminación. Las voces en - $\tilde{a}$ (revanche, avalanche, manche, planche, etc.) conservaron el género femenino invariable al pasar al español y portugués. La denotación del fr. guanche es la propia de un sustantivo inanimado que imposibilita tanto la diferenciación por sexo, como la ambigüedad, nunca podría entre franceses o gascones designar a un conjunto de personas.

Tampoco se explica que los hablantes acudieran a la nominalización deverbal bruta, en lugar de construir el gentilicio sobre el adjetivo disponible gueinçois, gueinchois, guenchois, guichois, proceso seguido en gentilicios toponímicos de morfología similar como La Guiche (ant. Guichia): guichois, -oise, laguichois, -oise (Arganchy > arganchois, -oise; Binche > binchois, -oise, La Guerche: guerchois, -oise, La Manche > manchois, -oise, Wanze > wanzois, -oise, etc.), o bien como el vasconismo Guiche (ant. Guisse) en Gascuña: guichot > guishot. ${ }^{19}$

El empleo de las formas guenchi, guenchois, guenchissant con función de calificativo personal no es idiomática en francés ni gascón, ni literal, ni figuradamente, en tanto que guenche, guanche se refiere a la dirección e intensidad de la acción, nunca al actor. En este caso el género del deverbal procede del sustantivo al que calificaba originalmente dentro de una expresión compuesta, omitido por elipsis: faire la tour guenche $>$ faire la guenche $>$ faire guenche.${ }^{20}$ Siendo una terminología frecuente en la chanson de geste hasta el siglo XIV, no aparece como atributo dicho de una persona en ningún texto, porque se limita a especificar que un determinado movimiento o maniobra (tour) son oblícuos (guanche), con carácter semántico acotado y exclusivo (cf. Llamas Pombo, 2004:790-91).

Aunque los seudogentilicios pueden construirse lúdicamente sobre lexemas originariamente de género femenino, cuya flexión queda inactiva por fusión a la raíz para formar remoquetes (el cañaílla, los cañaíllas, la cañaílla, habitantes de San Fernando, Cádiz), y sustraerse excepcionalmente a las desinencias categoriales del género mediante simildesinencias sobre el designativo enterizo (Ferreccio Podestá, 2006:181), la inexplicada elección, la inexplicada elección primordial de un sustantivo femenino unigénere en francés, en lugar del masculino que evidencia la documentación castellana de fines del siglo XV (el guanche, los guanches, la guancha), supone una discordancia formal difícil de sostener, a la vez que el etnónimo presenta rasgos característicos de los relictos léxicos indígenas, ${ }^{21}$ que todos los autores pueden admitir (Morera, 2007:631, 2014:283n14; Trapero y Santana Martel, 2018:I, 130-133, 140-141).

19 Acerca de la sufijación gentilicia en francés, v. Plénat, 2008.

20 Este proceso elíptico es típico en latín (la mano dextra $>$ la dextra) y pasó como norma general a los adjetivos y participios sustantivados de las lenguas romances. El deverbal guenche da lugar por elipsis a un substantif déadjectival neológico, cuyo género femenino es residuo de la concordancia gramatical otorgada por el sustantivo elidido (la tour, en francés medieval), siguiendo el principio de recuperabilidad de las elisiones como en español (Brucart 1987), para facilitar en el contexto lingüístico el reconocimiento de la expresión extendida precedente, a pesar de la caída del artículo: faire guenche.

21 N.B. ARV, BG-L.194-0395: 387r (1494). Diligenter atque praemetuenter inspicere. 


\section{Bibliografía:}

Almela Pérez, Ramón (2013): “Categoría, función y sentido de los gentilicios”. Anuario de Estudios Filológicos, 36:5-18.

- (2013): "Los sufijos gentilicios: un grupo tan indiscutible como erróneo". Revista Cálamo FASPE 61:12-21.

Baños, José Miguel (2009): Sintaxis del Latín Clásico. Madrid: Liceus.

Bastardas, Juan (1973): “El latín de los cristianos. Estado actual de su problemática". Boletín del Instituto de Estudios Helénicos de Barcelona 7.2:5-18.

Bocchetti, Carla (2006): "El Catálogo de las Naves y los Himnos Homéricos". Noua tellus 24.2:41-75.

Brodersen, Kai (1995): Terra Cognita. Studien zur römischen Raumerfassung, (Spudasmata 59). Hildesheim: Georg Olms.

Brucart, José María (1987): La elisión sintáctica en español. Bellaterra/Barcelona: Publicacions de la Universitat Autonoma de Barcelona.

Cardoso, Adriana (2002): A língua latino-portuguesa de notários do século XI. Análise de aspectos morfossintácticos de documentos do Mosteiro de Pendorada Tesis Doctoral, Tomo 1 [http://www.clul.ulisboa.pt/files/adriana_cardoso/vol1.pdf]. Lisboa: Universidade Nova de Lisboa.

Chávez Fajardo, Soledad y Kordić Riquelme, Raïssa. El gentilicio: consideraciones morfológicas. El caso del gentilicio en Chile. Santiago de Chile: [en prensa].

Company, Concepción (2014): "Las preposiciones de, des y desde”, in Sintaxis histórica de la lengua española. Tercera parte: Adverbios, preposiciones y conjunciones. Relaciones interoracionales. Concepción Company (dir.), Tomo 2, pp. 1343-1477. México: Universidad Nacional Autónoma de México, Instituto de Investigaciones Filológicas, Fondo de Cultura Económica.

Cruz Herrera, María del Pilar (1997): La formación de gentilicios, seudogentilicios y otros dictados tópicos en las comunidades de Madrid y Castilla-La Mancha, Tesis Doctoral inédita. Madrid: Universidad Autónoma de Madrid.

Dandrow, Edward (2017). "Ethnography and identity in Strabo's Geography”, in The Routledge Companion to Strabo. Daniela Dueck (ed.), pp. 113-124. London/New York: Routledge.

Dinarés Cabrerizo, Oriol (2014): "La onomástica como indicador de identidad en el Bajo Imperio romano. Una aproximación a las problemáticas analíticas". POLIS. Revista de ideas y formas políticas de la Antigüedad Clásica 26:51-80.

D’ors Pérez-Peix, Álvaro (1946): "Estudios sobre la Constitutio Antoniniana. III. Los Peregrini después del Edicto de Caracalla". Anuario de Historia del Derecho Español 17:586604.

Enterline, James Robert (2002): Erikson, Eskimos \& Columbus. Medieval European Knowledge of America. Baltimore: The Johns Hopkins University Press.

Ferreccio Podestá, Mario (2006): “Una singularidad en la formación de los gentilicios: irradiación, cognados y afines”. Onomázein 13.1: 177-189.

Ferreccio Podestá, Mario y Jocelin Hernández, Jorge (1992): El gentilicio. Identificación de una categoría onomasiológica. Santiago de Chile: Imprenta Irarrázabal.

García de La Fuente, Olegario (1981): “Consideraciones sobre el influjo hebreo en el latín bíblico". Emerita 49.2:307-342.

- (1987): "El latín bíblico y el latín cristiano en el marco del latín tardío". Analecta malacitana: Revista de la Sección de Filología de la Facultad de Filosofía y Letras 10.1:3-64. 
- (1989): "El latín bíblico y el latín cristiano: coincidencias y discrepancias" [Actas del I Simposio de Latín Cristiano], in Helmantica: Revista de filología clásica y hebrea, 40/121123:45-67. Salamanca: Universidad Pontificia.

- (1994): Latín bíblico y latín cristiano. Madrid: CEES.

García Gallarín, Consuelo (2003): "Los gentilicios en la historia del español", in Estudios ofrecidos al profesor José Jesús de Bustos Tovar. José Luis Girón Alconchel et al., Tomo 1, pp. 579-599. Madrid: Universidad Complutense, Editorial Complutense.

García Gallarín, Consuelo y García Gallarín, Celeste (1997): Deonomástica hispánica. Vocabulario científico, humanístico y jergal. Madrid: Universidad Complutense, Editorial Complutense.

García Moreno, Luis Agustín (1994): "Etnografía y paradoxografía en la historiografía latina de la república tardía y época augustea". POLIS. Revista de ideas y formas políticas de la Antigüedad Clásica 6:75-92.

García Padrón, Dolores (2012): “Tipos de alogentilicios y su descripción en los diccionarios académicos españoles", in Avances de lexicografia hispánica [Congreso Internacional de Lexicografía Hispánica, 4. 2010. Tarragona]. Antoni Nomdedeu Rull, Esther Forgas Berdet y María Bargalló Escrivà (coords.), Tomo I, pp. 147-154. Tarragona: Universitat Rovira i Virgili.

García Sánchez, Jairo Javier (Juillet-Décembre 2017): [Revisión del libro El gentilicio en español: aspectos teóricos y prácticos, de Marcial Morera (coord.)]. Revue de Linguistique Romane, 81.323-324:539-544.

Goetz, Hans-Werner (2003a): “Gens. Terminology and perception of the 'Germanic' peoples from late Antiquity to the early Middle Ages", in The Construction of Communities in the Early Middle Ages: Texts, Resources and Artefacts. Richard Corradini, Max Diesenberger y Helmut Reimitz (eds.), pp. 39-64. Leiden/Boston: BRILL.

- (2003b): "Gens, kings and kingdoms: the Franks", in Regna and gentes: the relationship between late antique and early medieval peoples and kingdoms in the transformation of the Roman world. Hans-Werner Goetz, Jörg Jarnut y Walter Pohl (eds.), pp. 307-344. Leiden/Boston: BRILL.

González Fernández, Rafael y Molina Gómez, José Antonio (2011): “Precisiones a las menciones de 'origo' con la fórmula 'domo' + topónimo/gentilicio en la epigrafía romana de Hispania”. Emerita 79.1: 1-29.

González García, Francisco Javier (1997): El Catálogo de las Naves. Mito y parentesco en la épica homérica. Madrid: Ediciones Clásicas.

González Luis, Francisco (1995): Oscilaciones entre género masculino y femenino documentadas en Latín medieval. Tesis doctoral [https://eprints.ucm.es/3370/]. Madrid: Universidad Complutense de Madrid.

- (2003): "Oscilaciones de género y declinación en la latinización de topónimos", in Lógos hellenikós: homenaje al profesor Gaspar Morocho Gayo. José María Nieto Ibáñez (coord.), Vol. 1, pp. 139-148.

González Saavedra, Berta (2015): Expresión de la procedencia en lenguas indoeuropeas antiguas: latín, griego e hitita. Tesis Doctoral [http://eprints.ucm.es/32775/1/T36269.pdf]. Madrid: Universidad Complutense de Madrid.

Hall, Jonathan M. (1997): Ethnic Identity in Greek Antiquity. Cambridge: Cambridge University Press.

— (October 1998): "Ethnic Identity in Greek Antiquity". Cambridge Archaeological Journal 8.2: $265-283$.

- (2002): Hellenicity: Between Ethnicity and Culture. Chicago/London: University of Chi- 
cago Press.

- (december 2015): “Ancient Greek ethnicities, towards a reassessment". Bulletin of the Institute of Classical Studies 58.2: 15-29.

Hernández Cabrera, Tomás (1998): Las preposiciones latinas en época clásica. Estudio funcional. Tesis Doctoral [ftp://tesis.bbtk.ull.es/ccssyhum/cs46.pdf]. La Laguna: Universidad de La Laguna.

Kajanto, Iiro (1965): The Latin cognomina [Commentationes Humanarum Litterarum 36.2]. Helsinki: Societas Scientiarum Fennica.

Kordić, Raïsssa y Ferreccio, Mario (2014): Topónimos y gentilicios de Chile. Santiago de Chile: RIL Editores.

Kordić Riquelme, Raïssa y Chávez Fajardo, Soledad (2017): “Qué se entiende por gentilicio. Aproximaciones onomasiologías, sintácticas y morfológicas. Prolegómenos”. Boletín de Filología 52.1:213-244.

Ledgeway, Adam (2012): From Latin to Romance. Morphosyntactic Typology and Change. Oxford: Oxford University Press.

Lipton, Wallace S. (1960-1961): "Imposed Verb Pronominalization in Medieval French and Provençal”. Romance Philology 14: 111-137.

Lisyová, Ol'ga (2005): “La derivación adjetival a partir de los nombres propios". Moenia 11: 249-268.

Lorenzo, Juan (1976): “Aportaciones al estudio léxico del latín de los cristianos”. Emerita 44.2: 357-372.

Llamas Pombo, Elena (2004): "Del francés medio g(u)anche al español guanche historia de un préstamo léxico", in Isla abierta: estudios franceses en memoria de Alejandro Cioranescu, José M. Oliver Frade (coord.) [X Coloquio de la Asociación de Profesores de Filología Francesa de la Universidad Española, 2001], Vol. II, pp. 783-802. La Laguna: Universidad de La Laguna.

Marcato, Carla (2009): Nomi di persona, nomi di luogo. Introduzione all'onomastica italiana. Bologna: Il Mulino.

Martín Padilla, Kenia (2015): “Los gentilicios en la tradición lingüística hispánica: Estado de la cuestión”, in Lingüística teórica y aplicada: nuevas perspectivas. Nekane Celayeta Gil et al. (eds.), pp. 139-152. Frankfurt am Main: Peterlang.

Molina Marín, Antonio Ignacio (2011): “Geographica: Ciencia del espacio y tradición narrativa de Homero a Cosmas Indicopleustes", in Antigüedad y Cristianismo. Monografias Históricas sobre la Antigüedad Tardía. Rafael González Fernández (ed.), XXVII. Murcia: Universidad de Murcia, Área de Historia Antigua.

Monjour, Alf (2002): "Die Behandlung der Deonomastika in der spanischen und portugiesischen Lexikographie", in Onomastik. Akten des 18. Internationalen Kongresses für Namenforschung (Trier, 12.-17. April 1993). Dieter Kremer (ed.), Tomo 5: Onomastik und Lexikographie. Deonomastik, pp. 277-285. Tübingen: Niemeyer.

Morera, Marcial (2007): Diccionario histórico-etimológico del habla canaria. Con ejemplos históricos y literarios. Puerto del Rosario: Cabildo Insular de Fuerteventura.

- (2012): "Presentación del proyecto de investigación 'Estudio global de los gentilicios de la lengua española", in Avances de lexicografia hispánica [Congreso Internacional de Lexicografia Hispánica, 4. 2010. Tarragona]. Antoni Nomdedeu Rull, Esther Forgas Berdet y María Bargalló Escrivà (coords.), Tomo 1, pp. 69-80. Tarragona: Universitat Rovira i Virgili.

- (2012): "Los gentilicios en español: su descripción lexicográfica", in XI Coloquio de Lexicografía y Lexicología “Enrique Carrión Ordóñez". Universidad Nacional Mayor de San Marcos, 4-5 de octubre de 2012. Lima: [en prensa]. 
- (2013): "Estudio global de los gentilicios de la lengua española: materiales americanos, nuevas consideraciones teóricas y gestión informática de los datos (FFI/201126256)", in IX Encuentro de Morfólogos [https://morforetem.files.wordpress.com/2013/06/estudio-global-de-los-gentilicios-de-la-lengua-espac3b1ola.pdf]. Universidad de Cádiz, 1618 de mayo de 2013.

- (2014): "Clasificación de los restos de la lengua guanche según su grado de integración en español”. Revista de Filología Española 94-2: 279-302.

- (2015): El gentilicio en español: Aspectos teóricos y prácticos. Madrid: Arco/Libros.

Moroldo, Arnaldo (2015): /W/ latin et germanique dans les domaines gallo-roman et italo-roman [http://sites.unice.fr/site/henneboi/SVG-lirces/images/stories/wlatgerm.pdf]. Université de Nice Sophia-Antipolis.

Muñoz Cordero, Flor Ángel y Ordóñez Arbizu, Carlos Andrés (2009): Los gentilicios e hipocorísticos en el Perú. Lima: [s.n.].

Navas Sánchez-Élez, María Victoria (2012): "Contribución a la deonomástica portuguesa", in La suerte de los nombres propios: léxico y ortografía Jorge Braga Riera ed., Madrid, Silex, pp. 87-127.

Ortega Ojeda, Gonzalo (2008): Catálogo de los gentilicios canarios. Islas Canarias: Academia Canaria de la Lengua.

- (2007): "Los gentilicios burlescos de Canarias". Revista de Filología de la Universidad de La Laguna [Homenaje a Antonio Lorenzo] 25: 495-503.

Ortuño Arregui, Manuel (2006-2008): “Los vocablos 'sarracenus' vs. 'maurus' en las cartas puebla valencianas". Revista de Historia Medieval 15: 255-275.

- (2016): "Latín de los cristianos. Aproximación lingüística". ArtyHum 20: 57-65.

Perea Yébenes, Sabino (2004-2005): "Las 'patrias' del soldado romano en el Alto Imperio". Espacio, tiempo y forma. Serie II, Historia antigua 17-18: 161-189.

Pereltsvaig, Asya y Lewis Martin W. (2015): The Indo-European Controversy. Facts and Fallacies in Historical Linguistics. Cambridge: Cambridge University Press.

Pérez Vigaray, Juan Manuel (2015): "Gentilicios y lexicografía", in El gentilicio en español: Aspectos teóricos y prácticos, Marcial Morera (coord.), pp. 245-302. Madrid: Arco/Libros.

Plénat, Marc (2008): "Quelques considérations sur la formation des gentilés", in La raison morphologique. Hommage à la mémoire de Danielle Corbin Sous, Bernard Fradin (dir.), pp. 155-174. Amsterdam/Philadelphia: John Benjamins Publishing Company.

Pohl, Walter (2014): "Romanness: a multiple identity and its changes". Early Medieval Europe 22.4: 406-418.

- (2015a): "Political uses of ethnicity in early medieval Europe", in Ethnicity as a Political Resource. Conceptualizations across Disciplines, Regions, and Periods University of Cologne Forum "Ethnicity as a Political Resource" (ed.), pp. 201-208. Bielefeld: transcript.

- (2015b): "Comparing Communities. The Limits of Typology". History and Anthropology 26.1: $18-35$.

Ramírez Olid, José Manuel (1988): "La influencia griega en el texto de Mateo de la Vetus Latina”. Analecta malacitana: Revista de la Sección de Filología de la Facultad de Filosofía y Letras 11.2: 401-414.

Reinhardt, Jan (2010): “El Proyecto de un 'Deonomasticon Iberorromanicum' (DIR)”. Zeitschrift für romanische Philologie 126: 593-601.

Sadak, Efrem Yildiz (2000): "Los arameísmos en la lengua castellana" in Cuestiones de actualidad en lengua española. Luis Santos Río et al. (coord.), pp. 205-216. Salamanca: Ediciones Universidad de Salamanca. 
Salway, Benet (1994): "What's in a Name? A Survey of Roman Onomastic Practice from c. 700 B.C. to A.D. 700". Journal of Roman Studies 84:124-145.

Schweickard, Wolfgang (1992): Deonomastik. Ableitungen auf der Basis von Eigennamen im Französischen (unter verglächender Berücksichtigung des Italienischen, Rumänischen und Spanischen). Tübingen: Niemeyer.

- (2002-2013): Deonomasticon Italicum. Dizionario storico dei derivati da nomi geografia e da nomi di persona. Tübingen: Niemeyer.

Solodow, Joseph B. (2010): Latin alive. The survival of Latin in English and the Romance Languages. Cambridge: Cambridge University Press.

Stan, Camelia (2015): "Some functions of the definite article in Old Romanian", in Diachronic Variation in Romanian. G. Pană Dindelegan et al., pp. 55-65. Newcastle upon Tyne: Cambridge Scholars Publishing.

Tabares Plasencia, Encarnación (2015): "La variación gentilicia, con especial atención a la variación fónico-gráfica”, in El gentilicio en español: Aspectos teóricos y prácticos, Marcial Morera (coord.), pp. 169-204. Madrid: Arco/Libros.

Trapero, Maximiano (2007): Estudios sobre el guanche. La lengua de los primeros habitantes de las Islas Canarias. Las Palmas de Gran Canaria: Fundación Canaria MAPFRE Guanarteme.

Trapero, Maximiano y Santana Martel, Eladio (2018): Diccionario de Toponimia de Canarias: Los Guanchismos. Las Palmas de Gran Canaria: Ediciones Idea.

Vlassopoulos, Kostas (december 2015): "Ethnicity and Greek history: re-examining our assumptions". Bulletin of the Institute of Classical Studies 58.2: 1-13.

Whittaker, Dick (2009): "Ethnic discourses on the frontiers of Roman Africa", in Ethnic Constructs in Antiquity: The Role of Power and Tradition, Ton Derks y Nico Roymans (eds.), pp. 189-205. Amsterdam: Amsterdam University Press. 